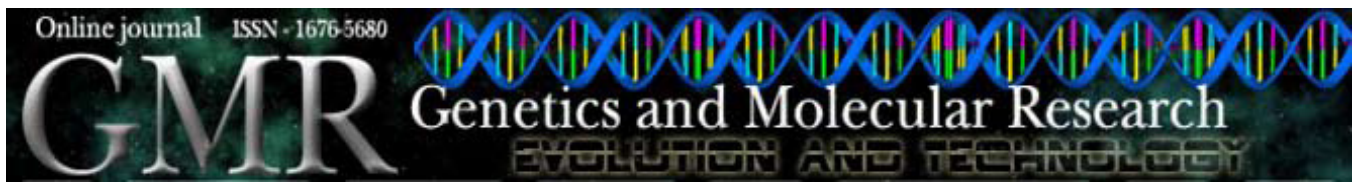

\title{
Initial stage of development and migratory behavior of Toxocara canis larvae in BALB/c mouse experimental model
}

\author{
M.L. Camparoto ${ }^{1}$, B. Fulan', C.M. Colli ${ }^{2}$, M.L. Paludo' \\ A.L. Falavigna-Guilherme ${ }^{2}$ and M.A. Fernandez ${ }^{1}$ \\ ${ }^{1}$ Departamento de Biologia Celular e Genética, Maringá, PR, Brasil \\ ${ }^{2}$ Departamento de Análises Clínicas, Universidade Estadual de Maringá, \\ Maringá, PR, Brasil \\ Corresponding author: M.A. Fernandez \\ E-mail: aparecidafernandez@gmail.com
}

Genet. Mol. Res. 7 (2): 444-450 (2008)

Received February 7, 2008

Accepted April 28, 2008

Published May 20, 2008

\begin{abstract}
In the present study, the initial developmental stage of Toxocara canis eggs and larvae, and number of recovered larvae from BALB/c mouse-infected organs are described. In vitro culture of $T$. canis detects the frequencies of interphasic, mitotic and embryonated eggs only within a 7-day period. Analysis by egg counting was carried out for 32 days. The results showed that at 7 days after cultivation, the frequency of larvae was $50.4 \%$ and that this frequency reached $52.8 \%$ in 32 days. In the experimental infection of BALB/c mice with $T$. canis, the number of recovered larvae statistically increased in the brain and liver, with doses of approximately 200 and 1000 eggs. After 7 days of infection, a larger number of larvae were obtained in the lung and liver, although a maximum amount was found in the brain after a 15- or 30-day post-infection period.
\end{abstract}

Key words: Toxocara canis; BALB/c mice; Larval recovery; Visceral larva migrans; Infection 


\section{INTRODUCTION}

There is epidemic evidence that Toxocara canis is a parasite with the highest incidence in zoonotic zones. Toxocara canis and T. cati, common ascarids in dogs and cats, are major etiological agents of toxocariasis (Magnaval et al., 2001). Human infection by Toxocara sp eggs is distributed worldwide and appears in variable frequencies, depending on factors related to children's hygienic and behavioral habitats (Aguiar-Santos et al., 2004). Children are most likely to be infected, probably because of their undeveloped immune system, the amount of eggs ingested (Habluetzel et al., 2003) and the frequency of reinfections (Chorazy and Richardson, 2005). Most patients who are seropositive for Toxocara spp show no clinical signs. However, sometimes it can cause fever, hepatosplenomegaly, pulmonary symptoms such as asthma, acute bronchitis, dermatological disorders, myositis, lymphadenopathy, and pseudorheumatic syndromes such as arthralgia with or without eosinophilia and anti-Toxocara sp antibodies (Lopez et al., 2002).

A wide range of animals, including mice, rabbits, monkeys, and humans, act as paratenic hosts (Lescano et al., 2004). When ingested, the larva batch penetrates the walls of the small intestine and disseminate in a hematogenous form through the soft tissues of the body (Anderson et al., 2005). According to the literature, the most commonly affected organs are the liver, lungs and eyes. The central nervous system, heart and skeletal muscles are less often affected.

Several studies with animal models have been developed, particularly to evaluate the effects of drugs in toxocariasis treatment. An effective drug against toxocariasis is still to be developed (Caumes, 2003; Satoh et al., 2005; Lescano et al., 2005). Due to low anthelmintic efficiency against diseases caused by the migration of nematode larvae in humans, cure is difficult (Magnaval et al., 1997; Moreira-Silva et al., 2004; Satoh et al., 2005; Hamilton et al., 2006). Smith (1991) reported that the migration pathway of larvae in humans and mice is similar, and lesions in experimental mouse models and humans are comparable. In fact, the animal model has been widely used to study toxocariasis. Recently, it has been demonstrated that infection of BALB/c mice with $T$. canis results in chronic pulmonary inflammation and a dominant TH2 type of immune response, regardless of inoculum size (Pinelli et al., 2005).

The aim of the present study was to optimize the time of different phases in initial stage of development of the T. canis eggs and larvae for quantification in BALB/c mouseinfected organs.

\section{MATERIAL AND METHODS}

\section{Biological material}

T. canis adult worms were recovered from naturally infected dogs, after routine de-worming by anthelmintic treatment. Eggs were collected from the uteri of 10 female worms for in vitro culture. After processing, the eggs were maintained in $2 \%$ formalin solution for 4 weeks at $28^{\circ} \mathrm{C}$, and the different phases of development were determined under light microscopy. Our experiments were adapted to oxygenate the cultures for 30 min/day. Eighteen BALB/c mice (9 males and 9 females), with 4-6 weeks of age, were 
orally infected, using a syringe fitted with a blunt needle, with approximately 200 and 1000 embryonated T. canis eggs. On days 7, 15 and 30 after inoculation, four mice were killed by cervical dislocation and larvae were recovered from brain, lungs, liver, and kidneys, after acid digestion, as described by Xi and Jin (1998). Larval counting in fixed samples was undertaken by microscopic analysis. Eighteen control mice uninfected were submitted to the same conditions.

\section{Statistical analysis}

The analysis was carried out at the $95 \%$ confidence limit. Kruskal-Wallis ANOVA was applied for results obtained by experimental infection in BALB/c mice to evaluate the influence of dose, gender and post-infection period on the frequency of recovered larvae in brain, lungs, liver, and kidneys. The Mann-Whitney method of multiple pair-wise comparisons was also applied to determine the differences between gender and post-infection period.

\section{RESULTS AND DISCUSSION}

The experiments were adapted to oxygenate the cultures for $30 \mathrm{~min} /$ day, and the larval developmental stage could be observed in only seven days. The data contrasted other studies that showed that the development of $T$. canis larvae needed at least one month (RodriguezCaballero et al., 2007).

The initial stage of T. canis development is shown in Figure 1 and Table 1. On the 7th day, the frequency of larvae was $50.4 \%$ and after 32 days this frequency reached $52.8 \%$. During this period, 44.4 and $2.8 \%$ of the eggs remained in interphase and mitosis, respectively. The efficiency of this method has been recently demonstrated by Rodriguez-Caballero et al. (2007) who reported equivalent quantities of eggs in interphase and mitosis in the first day of cultivation.
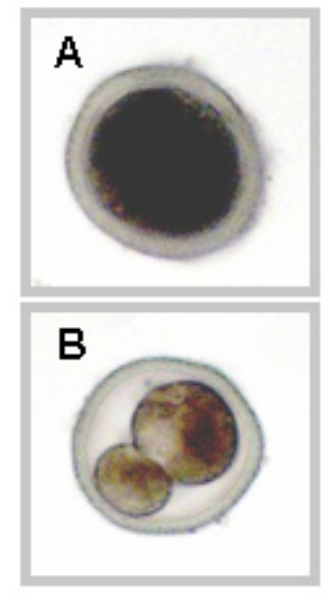
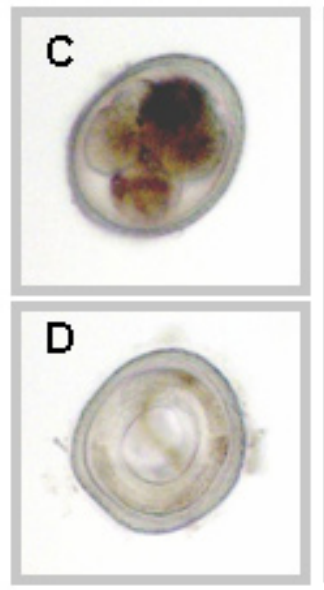

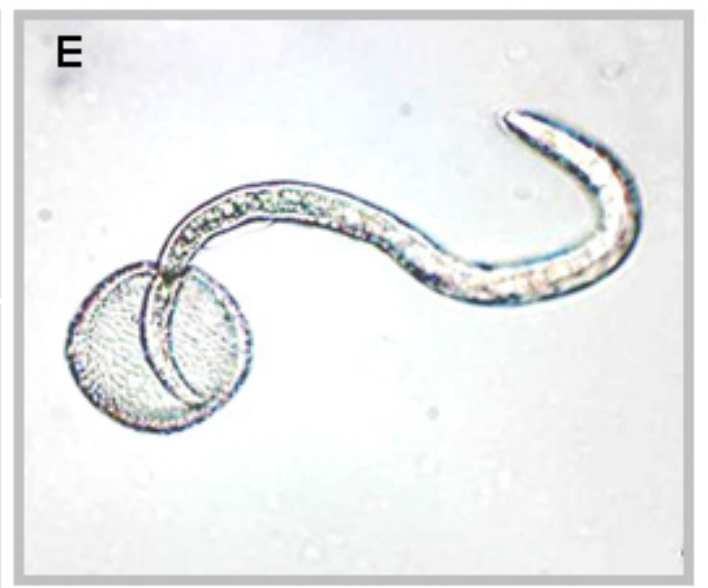

Figure 1. Initial stages of Toxocara canis development. Eggs in interphase (A), mitosis (B and C), embryonated egg with larva inside (D), and larva reaching egg (E). Phase contrast microscopy, 200X. 


\begin{tabular}{|c|c|c|c|c|}
\hline \multirow[t]{2}{*}{ Days } & \multicolumn{3}{|c|}{ Phases of development (\%) } & \multirow[t]{2}{*}{ Total cells analyzed } \\
\hline & I & MI & $\mathrm{L}$ & \\
\hline 1 & $53.2 \pm 2.8$ & $46.8 \pm 2.8$ & $0.0 \pm 0.0$ & 230 \\
\hline 5 & $56.0 \pm 2.3$ & $24.8 \pm 0.7$ & $19.2 \pm 2.9$ & 643 \\
\hline 7 & $49.3 \pm 6.8$ & $1.3 \pm 0.6$ & $50.4 \pm 6.3$ & 437 \\
\hline 10 & $51.8 \pm 9.4$ & $1.0 \pm 0.6$ & $43.8 \pm 8.8$ & 542 \\
\hline 15 & $56.2 \pm 20.4$ & $3.5 \pm 1.2$ & $40.4 \pm 21.8$ & 248 \\
\hline 32 & $44.4 \pm 7.5$ & $2.8 \pm 0.4$ & $52.8 \pm 1.7$ & 529 \\
\hline
\end{tabular}

$\mathrm{I}=$ interphase; $\mathrm{MI}=$ mitosis; $\mathrm{L}=$ larvae.

Our results showed that in the two tested egg doses, 200 and 1000 embryonated T. canis eggs, the number of recovered larvae in different organs was significant only for the brain and the liver $(\mathrm{P}=0.0010$ and 0.0004 , respectively), see Figures 2 and 3 . The important aspect of larval survival is that in the liver they may remain in a dormant state, triggering no response or only a weak response from the immunological system. In humans, this may cause serious ocular damage when they migrate to the retina, causing ocular larva migrans disease (Leone et al., 2006).

\section{$\square$ Male $\square$ Female}

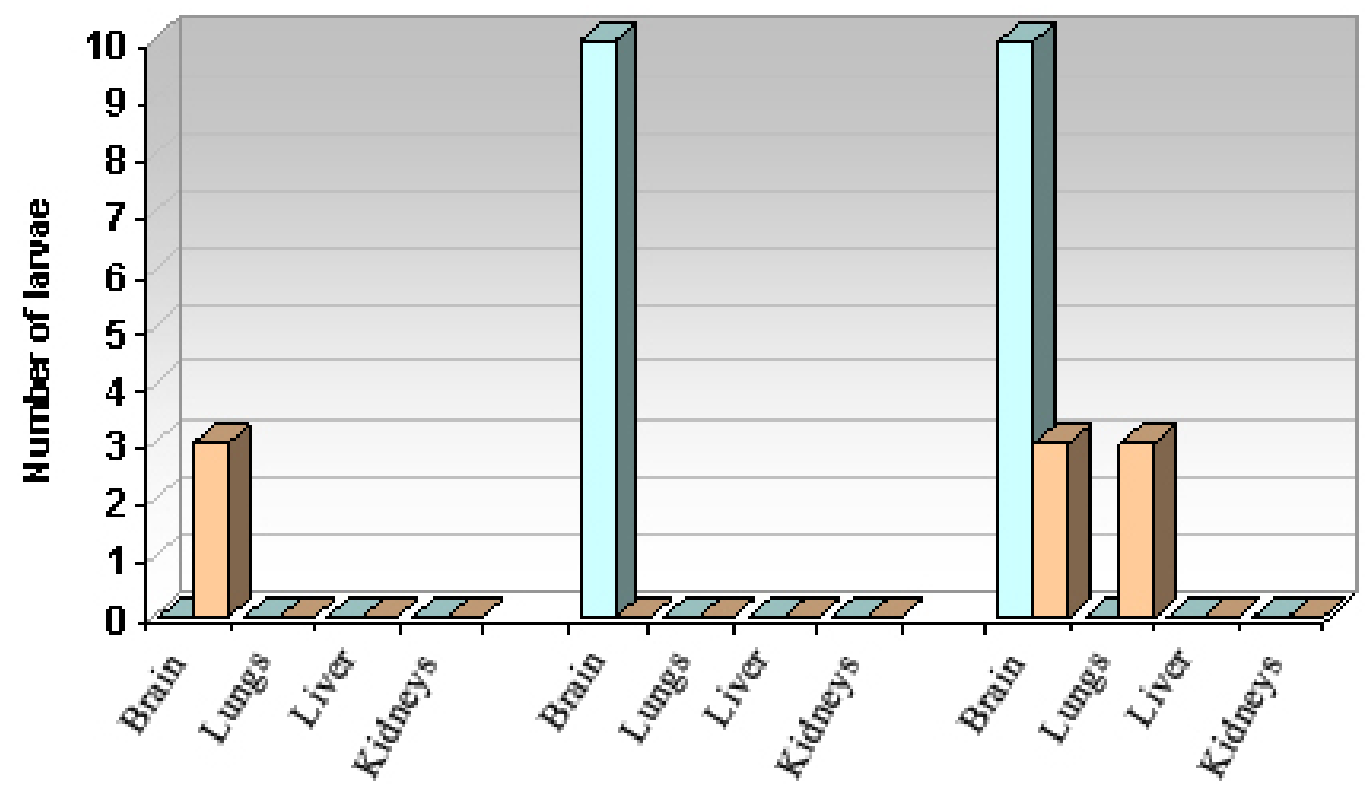

Figure 2. Mean percentage of total Toxocara canis larvae recovered from four organs of male and female BALB/c infected with a 200 -egg dose after 7,15 and 30 days post-infection. 


\section{Male $\square$ Female}

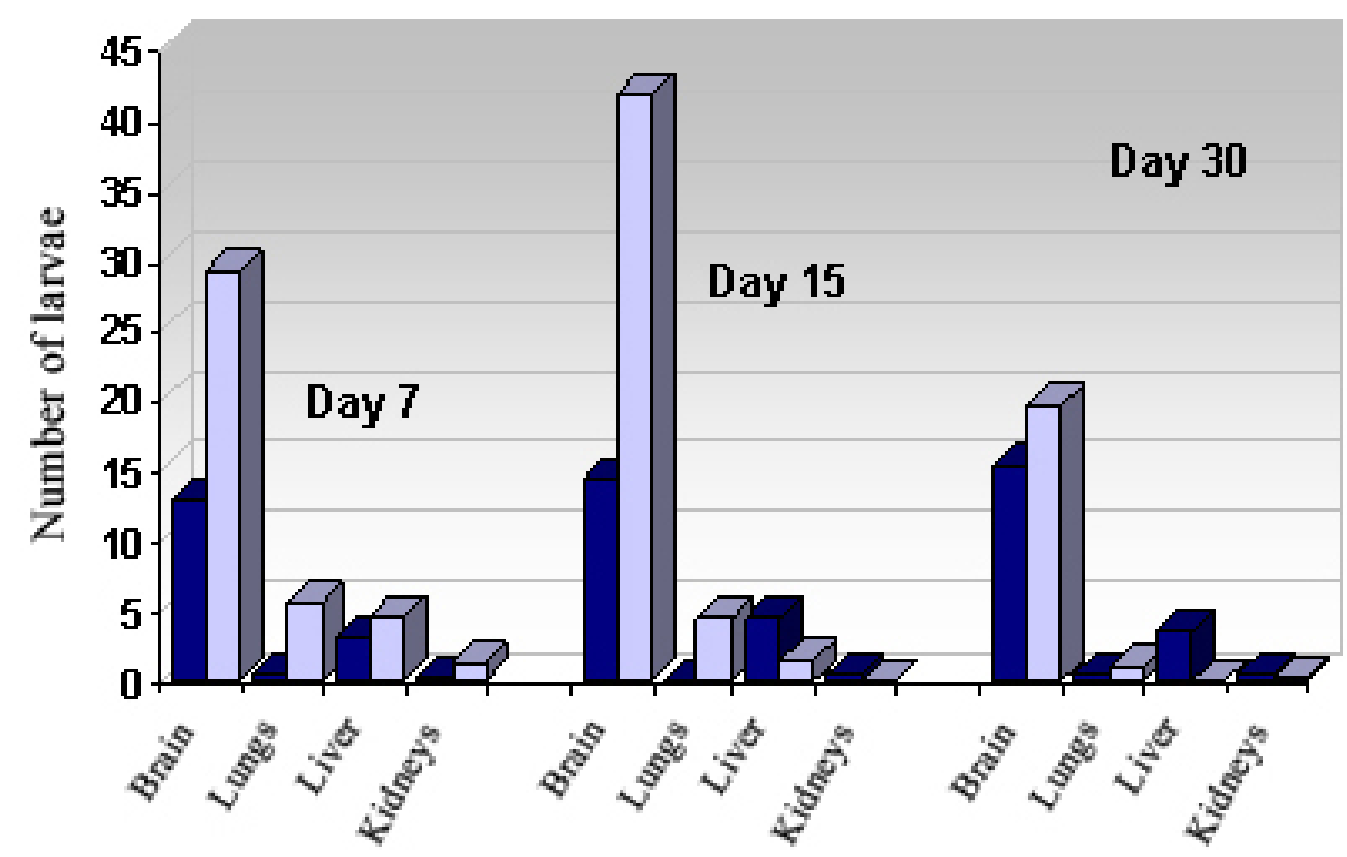

Figure 3. Mean percentage of total Toxocara canis larvae recovered from four organs of male and female BALB/c infected with a 1000-egg dose after 7, 15 and 30 days post-infection.

There was a significant difference in larval recovery when gender or days of infection were taken into account. The smaller dosage (200 eggs), close to natural infection, allowed the recovery of a low percentage of larvae. In this experimental condition, larvae were found in the brain and lung of female BALB/c on the 7th day after infection, while in males the larvae were recovered only in the brain on the 15 th day. These data agree with those described by Xi and Jin (1998) and Lescano et al. (2004).

More larvae were also recovered from the brain with doses of 1000 eggs. There was a significant effect at 7 days post-infection on larval recovery from lungs $(\mathrm{P}=0.033896)$ or liver $(\mathrm{P}$ $=0.043115)$. Higher larval recovery from the brain of BALB/c occurred on the 15th day in the female and on the 30th day in the male $(\mathrm{P}=0.049535)$. Pinelli et al. (2005) showed that, within the same experimental conditions, recovered T. canis larvae increased in the lung on the 7th day and decreased thereafter, with an accumulation in the brain up to the 56th day. Studies on cerebral toxocariasis have shown that the infective dose influences not only the larval burden in the brain but also the behavior of Toxocara-infected mice (Cox and Holland, 1998). According to AboShehada and Herbert (1989), when the larvae reach the liver and the lungs (hepato-pulmonary phases), the larvae migrate throughout the body and accumulate mainly in the carcass and in the brain (myotropic-neurotropic phases). Pinelli et al. (2007) showed that T. canis larvae migrated to the lungs of infected BALB/c mice and caused tissue damage and pulmonary inflammation. 
Although in experimental animals the larvae frequently migrate to the brain, clinical involvement of the nervous system in visceral larva migrans is rare (Moreira-Silva et al., 2004). Hamilton et al. (2006) studied cerebral toxocariasis in seven strains of mice and chose two strains of BALB/c (susceptible and resistant) infected with 2000 embryonated eggs of $T$. cani and observed that the larvae cannot be a reliable indicator of susceptibility or resistance to T. canis infection. Lescano et al. (2004) studied the recovery of T. canis larvae in Rathus norvegicus infected with approximately 500 embryonated eggs. The highest number of recovered larvae occurred in the liver, especially between the third and fifth days after infection, while in the brain the highest values were obtained between the 15 th and 60th days after infection.

Current analysis suggests the influence of the animal's sex, or rather, a possible hormonal interference in the female. Our results raise new questions on $T$. canis biology as well as provide information on larva migratory behavior in experimental models.

\section{ACKNOWLEDGMENTS}

We would like to thank Valmir Peron and Marli Licero Schuete Silva for their dedicated technical assistance and the Universidade Estadual de Maringá for its facilities (COMCAP laboratories). M.L. Camparoto received a post-doctoral fellowship from CNPq.

\section{REFERENCES}

Abo-Shehada MN and Herbert IV (1989). Variations in innate resistance to experimental Toxocara canis infection in two strains of mice. Vet. Parasitol. 33: 297-307.

Aguiar-Santos AM, Andrade LD, Medeiros Z, Chieffi PP, et al. (2004). Human toxocariasis: frequency of anti-Toxocara antibodies in children and adolescents from an outpatient clinic for lymphatic filariasis in Recife, Northeast Brazil. Rev. Inst. Med. Trop. São Paulo 46: 81-85.

Anderson A, Fordham LA, Bula ML and Blatt J (2005). Visceral larval migrans masquerading as metastatic disease in a toddler with Wilms tumor. Pediatric Radiol. 36: 173-282.

Caumes E (2003). Treatment of cutaneous larva migrans and Toxocara infection. Fund. Clin. Pharmacol. 17: 213-216.

Chorazy ML and Richardson DJ (2005). A survey of environmental contamination with ascarid ova, Wallingford, Connecticut. Vector Borne Zoonotic. Dis. 5: 33-39.

Cox DM and Holland CV (1998). The relationship between numbers of larvae recovered from the brain of Toxocara canisinfected mice and social behaviour and anxiety in the host. Parasitology 116 (Pt 6): 579-594.

Habluetzel A, Traldi G, Ruggieri S, Attili AR, et al. (2003). An estimation of Toxocara canis prevalence in dogs, environmental egg contamination and risk of human infection in the Marche region of Italy. Vet. Parasitol. 113: 243-252.

Hamilton CM, Stafford P, Pinelli E and Holland CV (2006). A murine model for cerebral toxocariasis: characterization of host susceptibility and behaviour. Parasitology 132: 791-801.

Leone N, Baronio M, Todros L, David E, et al. (2006). Hepatic involvement in larva migrans of Toxocara canis: report of a case with pathological and radiological findings. Dig. Liver Dis. 38: 511-514.

Lescano SZ, Queiroz ML and Chieffi PP (2004). Larval recovery of Toxocara canis in organs and tissues of experimentally infected Rattus norvegicus. Mem. Inst. Oswaldo Cruz 99: 627-628.

Lescano SZ, Chieffi PP, Amato Neto V, Ikai DK, et al. (2005). Anti-helmínticos na toxocaríase experimental: efeito na recuperação de larvas de Toxocara canis e na resposta humoral. J. Bras. Patol. Med. Lab. 41: 21-24.

Lopez MLA, Martin G, Chamorro MDC and Alonso JM (2002). Toxocariasis in children from a subtropical region. Medicina 65: 226-230.

Magnaval JF, Galindo V, Glickman LT and Clanet M (1997). Human Toxocara infection of the central nervous system and neurological disorders: a case-control study. Parasitology 115 (Pt 5): 537-543.

Magnaval JF, Berry A, Fabre R and Morassin B (2001). Eosinophil cationic protein as a possible marker of active human Toxocara infection. Allergy 56: 1096-1099.

Moreira-Silva SF, Rodrigues MG, Pimenta JL, Gomes CP, et al. (2004). Toxocariasis of the central nervous system: with 
report of two cases. Rev. Soc. Bras. Med. Trop. 37: 169-174.

Pinelli E, Withagen C, Fonville M, Verlaan A, et al. (2005). Persistent airway hyper-responsiveness and inflammation in Toxocara canis-infected BALB/c mice. Clin. Exp. Allergy 35: 826-832.

Pinelli E, Brandes S, Dormans J, Fonville M, et al. (2007). Toxocara canis: effect of inoculum size on pulmonary pathology and cytokine expression in BALB/c mice. Exp. Parasitol. 115: 76-82.

Rodriguez-Caballero A, Luna-Ochoa RI, Ponce-Macotela M, Peralata-Abarca GE, et al. (2007). A simple and inexpensive in vitro method for retrieving fertilized Toxocara canis eggs. Parasitol. Res. 101: 829-832.

Satoh T, Akao N, Matsuhashi R, Koike K, et al. (2005). Inhibitory effect of isoquinoline alkaloids on movement of secondstage larvae of Toxocara canis. Biol. Pharm. Bull 25: 1651-1654.

Smith HV (1991). Immune evasion and immunopathology in Toxocara canis infection. In: Parasitic nematodes - antigens, membranes and genes (Kennedy MW, ed.). Taylor and Francis, London, 116-139.

Xi WG and Jin LZ (1998). A novel method for the recovery of Toxocara canis in mice. J. Helminthol. 72: 183-184. 